\title{
MODEL KONSEPTUAL PENDIDIKAN KESEHATAN GIGI MENGGUNAKAN MUSIK TARI DAN LAGU BAGI ANAK DOWN SYNDROM
}

\section{CONCEPTUAL MODEL FOR DENTAL HEALTH EDUCATION USING DANCE AND SONG MUSIC FOR CHILDREN DOWN SYNDROM}

\author{
Rena Setiana Primawati ${ }^{1^{*}}$ \\ ${ }^{1}$ Jurusan Keperawatan Gigi Poltekkes Kemenkes Tasikmalaya \\ renakeysharazka@gmail.com
}

Kata kunci:

Model konseptual pendidikan kesehatan gigi, musik tari dan lagum down syndrom

\section{ABSTRAK}

Prevalensi penyakit periodontal pada anak down syndrom lebih tinggi daripada anak sehat. Selain penyakit periodontal, anak down syndrom juga memiliki karakter yang khas seperti oral hygiene (indeks kebersihan gigi dan mulut) yang buruk. .Tindakan promotif dan preventif harus ditekankan karena tindakan kuratif memerlukan penanganan yang lebih kompleks serta biaya yang lebih besar. Upaya promotif dilakukan melalui pendidikan kesehatan gigi dan mulut (Dental Health Education) khususnya edukasi tentang pemeliharaan oral hygiene. Salah satu kekurangan dari anak down syndrom adalah sulitnya memahami dan menerima materi dari penyuluhan kesehatan gigi dan mulut apabila diberikan dengan metode standar oleh karena itu penulis mencoba memodifikasi metode penyuluhan kesehatan gigi dan mulut dengan menggunakan musik, lagu dan tari. Tujuan Penelitiana adalah adalah membuat model konseptual PKG menggunakan musik, tari dan lagu. Hasil Penelitian berdasarkan penilaian para ahli menujukan bahwa media layak digunakan bagi anak down syndrom.

\section{ABSTRACT}

Key word:

Conceptual models of dental health education, dance music and songs, down syndrome
The prevalence of periodontal disease in children with Down Syndrome is higher than that of healthy children. In addition to periodontal disease, children with Down syndrome also have distinctive characteristics such as poor oral hygiene. Promotive and preventive actions must be emphasized because curative actions require more complex handling and greater costs. Promotive efforts are carried out through dental and oral health education (Dental Health Education) especially education on oral hygiene maintenance. One of the disadvantages of children with Down Syndrome is the difficulty of understanding and accepting material from oral health counseling when provided with standard methods, therefore the author tries to modify the oral health counseling method by using music, songs and dance. The aim of the Research is to create a conceptual model of PKG using music, dance and song. The results of the study based on the 


\section{PENDAHULUAN}

Insiden kecacatan down syndrom di Indonesia memiliki nilai sebesar $0,12 \%$ pada tahun 2010 dan terjadi peningkatan sebesar $0,13 \%$ pada tahun 2013. Prevalensi penyakit periodontal pada anak down syndrom lebih tinggi daripada anak sehat. Selain penyakit periodontal, anak down syndrom juga memiliki karakter yang khas seperti oral hygiene (indeks kebersihan gigi dan mulut) yang buruk. ${ }^{1,2}$. Down Syndrom atau Trisomy merupakan kelainan genetik karena orang dengan down syndrom memiliki 3 kromosom pada trisomi ke 21 dimana pada orang normal hanya memiliki 2 kromosom saja. Kelebihan kromosom ini akan mengubah keseimbangan genetik pada tubuh dan mengakibatkan perubahan karakteristik fisik dan kemampuan intelektual, serta gangguan dalam fungsi fisiologis tubuh manusia. ${ }^{4}$

Berdasarkan tingkatan IQ, maka anak down syndrom termasuk ke dalam klasifikasi tunagrahita sedang yaitu dengan kisaran IQ antara 40 sampai dengan 55. Anak tunagrahita seperti ini disebut down syndrom karena memiliki karakter berbeda dibandingkan dengan anak tunagrahita lainnya. Mereka memiliki raut muka seolah olah menyerupai seperti orang mongol dengan ciri ciri mata sipit dan miring, hidung yang datar, lidah tebal dan kepala cenderung pipih. ${ }^{5}$

Keterbatasan fungsi intelektual disertai dengan berbagai kekurangan atau hambatan dalam fungsi perilaku adaptif atau motorik ini mengakibatkan anak down syndrom kurang mandiri mengurus diri sendiri termasuk untuk menjaga kebersihan gigi dan mulutnya. ${ }^{7-9}$ Salah satu karakteristik anak down syndrom adalah membutuhkan waktu yang relatif lama dalam bereaksi pada situasi yang baru dan memiliki kecemasan yang tinggi, sebetulnya telah ada mata pembelajaran bina gosok gigi namun pada pelaksanaanya hanya berorientasi pada kurikulum tanpa memperhatikan derajat kesehatan gigi dan mulut, selain itu metode yang disampaikan pun hanya metode standar sehingga kurang menarik bagi anak down syndrom. ${ }^{13,14}$

Penyampaian materi peyuluhan kepada sasaran selain harus sesuai dengan metode yang akan digunakan juga dipengaruhi oleh ada tidak alat bantu dan sarana media pendukung untuk penyampaian. Penyuluhan dengan menggunakan musik, tari dan lagu merupakan salah satu cara untuk mempertunjukan secara langsung kepada subjek bahkan subjek penelitian terlibat langsung pada pengucapakan lagu dan mengikuti gerakan yang terdapat di dalam lagu tersebut. ${ }^{15}$

\section{METODE}

Penelitian ini menggunakan metode campuran (Mixed Method). Dimana penelitian menggunakan dua tahapan yaitu penelitian kualitatif terlebih dahulu untuk menganalisis dan membuat desain musik, tari dan lagu selanjutnya diikuti oleh penelitian kuantitatif untuk menilai kelayakan musik, tari dan lagu yang dilakukan oleh 12 ahli. Terdiri dari 2 orang ahli Media, 2 orang ahli PKG, 2 orang ahli Kedokteran Gigi anak, 2 orang ahli Pendidikan luar Biasa dan 2 orang ahli seni musik dan Tari. 


\section{HASIL DAN PEMBAHASAN}

1. Hasil Penelitian kualitatif yang didapatkan dari hasil Wawancara

Hasil dari penelitian ini terdiri dari hasil penelitian kualitatif yang merupakan hasil wawancara kepada orang tua anak down syndrom dan juga hasil penelitian kuantitatif merupakan penilaian kelayakan media oleh para ahli yang diolah menggunakan permodelan Rasch dengan Winstep.

Hasil Penelitian kualitatif yang didapatkan dari hasil wawancara kepada orang tua anak down syndrom melalui Focus Grup Discusion adalah musik, tari dan lagu yang direkomendasikan orang tua adalah musik dengan irama ceria dengan lirik sederhana dan diulang ulang dan dengan gerakan tarian yang mudah seperti gerakan senam aerobik.

Berdasarkan hasil wawancara tersebut akhirnya peneliti membuat rekaman musik dan lagu tentang menyikat gigi selanjutnya untuk gerakan tariannya dilakukan rekaman menggunakan kamera.

2. Hasil Penilaian Kelayakan Media oleh ahli

Hasil penilaian kelayakan media oleh para ahli diolah dengan menggunakan permodelan Rasch menggunakan perangkat Lunak Winstep versi 3.73 dan diperoleh pengelompokan kriteria rerata logit. Interpretasi penilaian terbagi menjadi kategori sangat sulit disetujui , sulit disetujui, mudah disetujui dan sangat mudah disetujui. Pada rerata logit lebih dari 0,0 logit +1 SD merupakan butir indikator yang sesuai, lebih besar dari +1 SD adalah sulit disetujui pada logit 0,0 logit -1 SD merupakan butir indikator yang mudah disetujui dan lebih kecil dari -1 adalah sangat mudah disetujui. Berdasarkan interpretasi tersebut pada butir butir yang sulit disetujui harus dilakukan perbaikan media sesuai dengan saran ahli dan pada akhirnya dapat disimpulkan bahwa media Mutalagi layak dan dapat dipergunakan untuk penelitian

Hasil Penilaian oleh ahli pendidikan kesehatan gigi dapat dilihat pada sebaran peta wright pada gambar 1.1

Person - MAP - Item

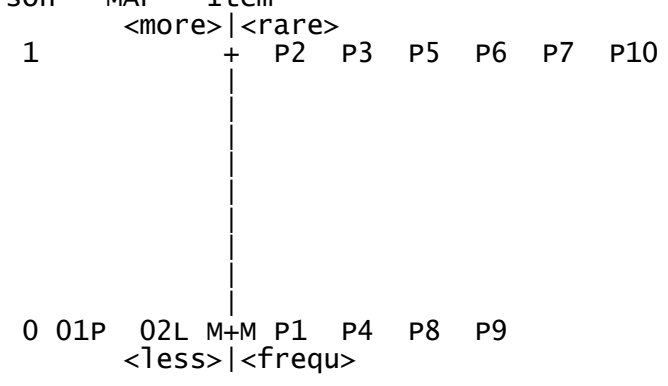

Gambar 1 Peta wright hasil penilaian oleh ahli pendidikan kesehatan gigi.

Berdasarkan sebaran peta wright (person item map) hasil penilaian Mutalagi oleh ahli pendidikan kesehatan gigi diatas dapat disimpulkan bahwa semua item sesuai dengan kriteria rerata logit yaitu berada pada nilai 0,0 dan logit +1 .

Hasil analisis penilaian Mutalagi oleh ahli media dapat dilihat pada sebaran peta wright pada gambar 2 


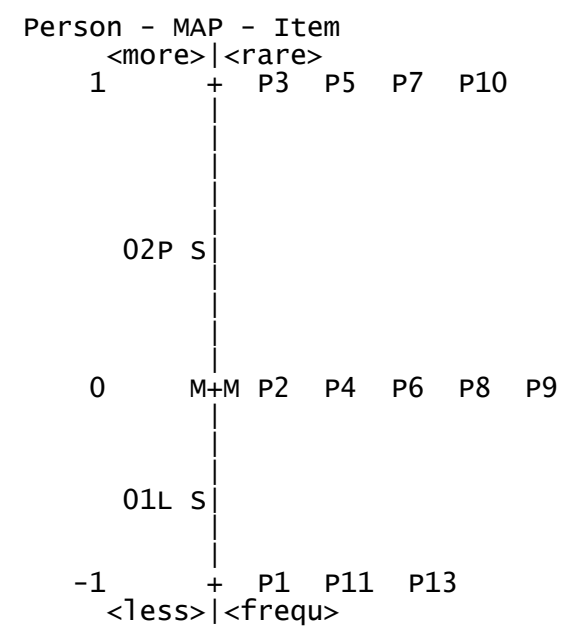

Gambar 2 Peta wright hasil penilaian oleh ahli media.

Berdasarkan sebaran peta wright (person item map) hasil penilaian Mutalagi oleh ahli media diatas dapat disimpulkan bahwa delapan item pada kriteria sesuai dengan kriteria rerata logit yaitu berada pada nilai 0,0 dan +1 , tiga item pada kriteria mudah disetujui dengan kriteria rerata logit berada pada nilai -1 .

Hasil Penilaian oleh ahli kesehatan gigi anak dapat dilihat pada sebaran peta wright pada gambar 3

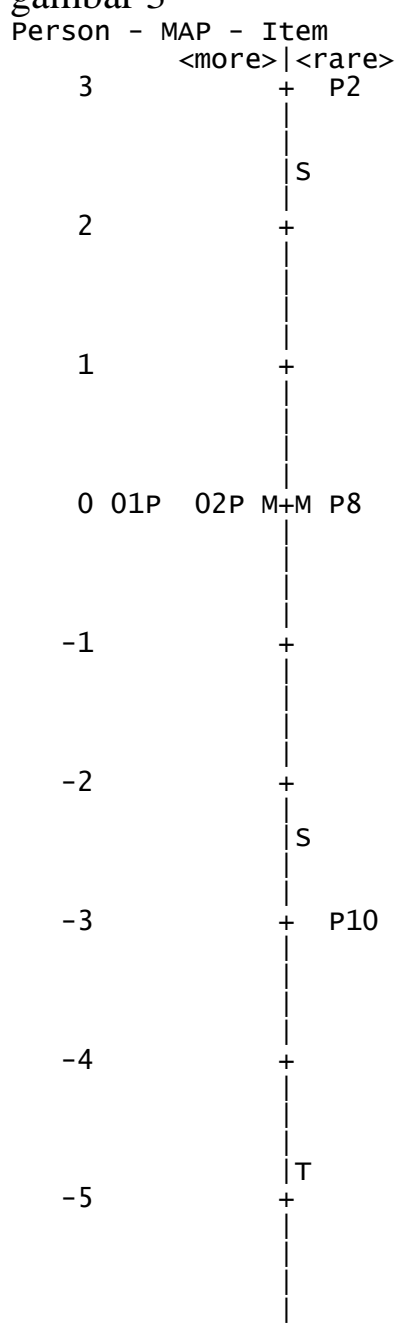




$$
\begin{array}{llllllll}
+ \text { Pless }>\mid<\text { frequ> } & \text { P4 } & \text { P5 } & \text { P6 } & \text { P7 } & \text { P9 } & \text { P11 }
\end{array}
$$

Berdasarkan sebaran peta wright (person item map) hasil penilaian Mutalagi oleh ahli kesehatan gigi anak diatas dapat disimpulkan bahwa satu item pada kriteria sulit disetujui dengan kriteria rerata logit yaitu berada pada nilai +3 dan, satu item pada ktiteria sesuai dengan kriteria rerata logit berada pada nilai 0,0 . Sembilan item pada kriteria sangat mudah disetujui dengan kriteria rerata logit berada pada nilai lebih dari -3 .

Hasil analisis penilaian Mutalagi oleh ahli pendidikan luar biasa dapat dilihat pada sebaran peta wright pada gambar 4

Person - MAP - Item

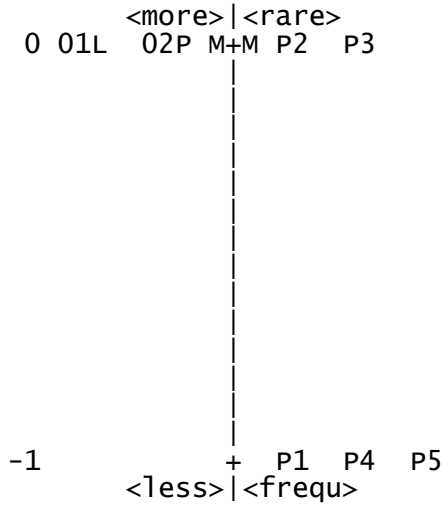

Gambar 4 Peta Wright hasil penilaian Mutalagi oleh ahli pendidikan luar biasa

Berdasarkan sebaran peta wright (person item map) hasil penilaian Mutalagi oleh ahli pendidikan luar biasa diatas dapat disimpulkan bahwa dua item pada kriteria sesuai dengan kriteria rerata logit yaitu berada pada nilai 0,0 dan tiga item pada ktiteria mudah disetujui dengan kriteria rerata logit berada pada nilai -1

Hasil analisis penilaian Mutalagi oleh ahli seni musik dan tari dapat dilihat pada sebaran peta wright pada gambar 5

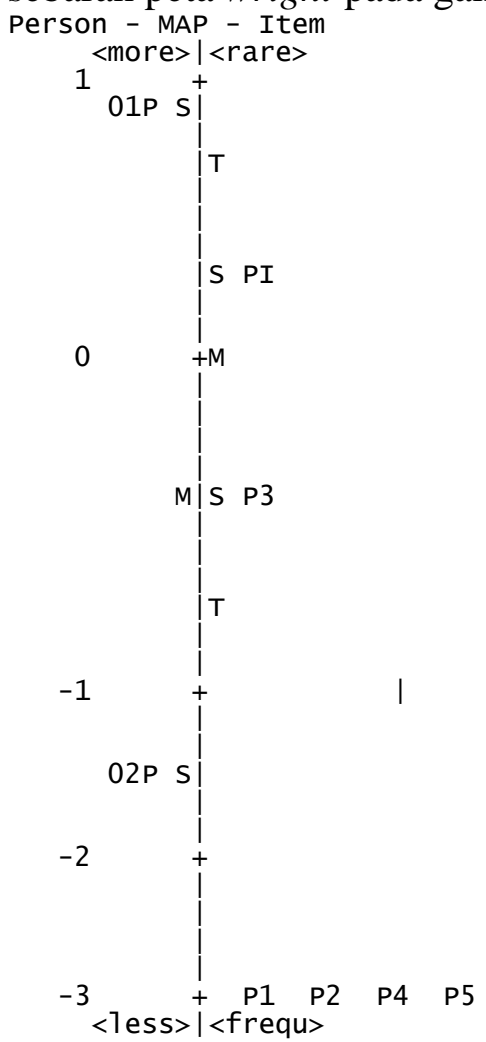

Gambar 5 Peta Wright hasil Penilaian Mutalagi oleh ahli seni musik dan tari 
Berdasarkan sebaran peta wright (person item map) hasil penilaian Mutalagi oleh ahli seni musik dan tari diatas dapat disimpulkan bahwa dua item pada kriteria sesuai dengan kriteria rerata logit yaitu berada pada nilai 0,0 dan +1 . Empat item pada kriteria sangat mudah disetujui dengan kriteria rerata logit berada pada nilai -3

\section{KESIMPULAN}

Model konseptual pendidikan kesehatan gigi menggunakan media musik, tari dan lagu (Mutalagi) yang telah dikembangkan layak digunakan bagi anak down syndrom.Hal tersebut sesuai dengan penilaian yang telah dilakukan oleh beberapa ahli (Expert Judgement). Hasil penilaian kelayakan media oleh para ahli diolah dengan menggunakan permodelan Rasch menggunakan perangkat Lunak Winstep versi 3.73 dan diperoleh pengelompokan kriteria rerata logit berada pada nilai 0,0 logit -1 SD merupakan butir indikator yang mudah disetujui dan lebih kecil dari -1 yaitu sangat mudah disetujui.

\section{DAFTAR PUSTAKA}

1. Rizqia Ayu wulandari SC, Niluh Ringga. Analisis Perbedaan Jumlah Neutrofil antara Anak Down Syndrom dan anak sehat, Study pada SLB-C Widya Bakti Semarang dan MI Mirfaul Ulum. Odonti Dental Journal. 2017;4(1).

2. Riset Kesehatan Dasar, (2013).

3. Megananda Hiranya Putri TW, Hetty Anggrawati. Pengaruh Penggunaan Modul Edukasi Kesehatan Gigi dan Mulut terhadap Pengetahuan dan Keterampilan Keluarga yang Memiliki Anak dengan Down Syndrom. Kementerian Kesehatan Republik Indonesia Poltekkes Bandung. 2016.

4. Dessay. Down Syndrom : a Review of Literature, J. Oral Surgery, Oral Medicine, Oral Pathologi, Oral Radiologi and Endodontology. 2007.

5. Hana Maryaatussalam RM, Henri Nusantara. Kegiatan Bernyanyi pada Siswa Down Syndrom di SLB-C Yayasan Karya Bakti Garut. Jurusan Pendidikan Seni Musik. 2013;1(3).

6. EM W. Clinical Practice of dental Hygienist. Massachusett USA: 2005.

7. Illum NO, Gradel KO. Parents' assessments of disability in their children using WHO ICF-CY joined body functions and activity codes related to everyday life. European Journal of Paediatric Neurology. 2017;21:e203.

8. Sandy LPA, Priyono B, Widyanti N. Pengaruh pelatihan menggosok gigi dengan pendekatan Program Pembelajaran Individual (PPI) terhadap peningkatan status kebersihan gigi dan mulut pada anak disabilitas intelektual sedang. Majalah Kedokteran Gigi Indonesia. 2016;2(2):80.

9. Fiona Salsabila AMM. Ketika anaku "TAK SAMA": Interpretatif Phenomenological Analysis tentang Pengalaman ayah mengasuh anak Down Syndrom Jurnal Empaty

10. DM A. Pola Status Kesehatan Gigi dan Pemanfaatan Pelayanan Kesehatan Gigi dan Mulut Indonesia

11. Manish Jain AM, Santhosh Kumar,

12. Rushabh J. Dagli, Prabu Duraiswamy, Kulkarni aS. Dentition status and treatment needs among children with impaired hearing attending a special school for the deaf and mute in Udaipur, India Manish Jain, Anmol Mathur, Santhosh Kumar, Rushabh J. Dagli, Prabu Duraiswamy and Suhas Kulkarni. Journal of Oral Science. 2008;50(2).

13. Buda LV. Ensuring Maintenance of Oral Hygiene in Persons with Special Needs. Dental clinics of North America. 2016 Jul;60(3):593-604.

14. Ricky Teguh Budiyanto AS, Sugiarto. Efektivitas Terapi dengan Pemberian Teknik Dasar Futsal untuk Meningkatkan Keterampilan Motorik Kasar pada Tuna Grahita Ringan. Jurnal Media Ilmu Keolahragaan Indonesia 2017;7(2). 
Home page: http://ejurnal.poltekkestasikmalaya.ac.id/index.php/jikg/index

15. Nenden A. Efektifitas Multi metode dalam meningkatkan kemampuan cara bagi makan bagi anak tunagrahita Sedang Kelas III di SLBN 35 PAINAN E JUPEKhu (Jurnal Ilmiah Pendidkan Khusus) 2014 ; 3 (1) 